\title{
Health related quality of life in untreated and treated patients with AIS. Study III: trunk appearance and self-image
}

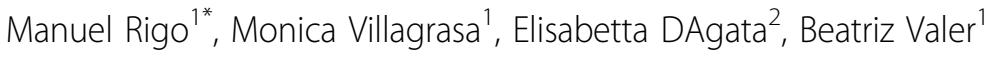 \\ From 11th International Conference on Conservative Management of Spinal Deformities - SOSORT 2014 \\ Annual Meeting \\ Wiesbaden, Germany. 8-10 May 2014
}

\section{Background}

The relationship between scoliosis magnitude, HRQL and Self Perception of Trunk Deformity is not clear. To better understand this, a data collection including age, main thoracic and lumbar or thoracolumbar Cob angle, Trunk Asymmetry Perception Scale TAPS, SRS-22 and current treatment was started involving all untreated and treated patients with idiopathic scoliosis attending a rehabilitation clinic, 10 years of age or older at the time of consultation. The data have been retrospectively analyzed and are presented in several studies. This is the study III.

\section{Purpose}

Self- Image in people with Scoliosis is usually the lowest HRQOL factor in comparison to the others. The aim of this study was to assess whether patients with a worse Self-Image might have an "aberrant" perception of their deformity in comparison with people showing a better Self Image.

\section{Methods}

$\mathrm{N}=240$; mean age $19.3+10.3$ y (10-62), mean Cobb thoracic $33.7^{\circ}+13.8$, lumbar or thoracolumbar $29.7+$ 12.7. SPSS was used for statistics.

\section{Results}

In the group with better Self-Image the correlations between TAPS and Cobb angles (Thoracic: $r=-.5$; Lumbar/TL: $r=-.47)$ were similar to the ones of the group with worse Self-Image ( $r=-.5$ and $r=-.44$, respectively).
Furthermore, in the whole population, the correlations between TAPS and Cobb angles (Thoracic: $r=-.6$; Lumbar/TL: $r=-.5$ ) were similar to the correlation between TAPS and SRS-22 SI $(r=.5)$; while the correlations between SI and Cobb Angles (Thoracic: $r=-.3$; Lumbar/ $\mathrm{TL}: \mathrm{r}=-.3$ ) were the lowest ones. All these correlations were statistically significant $(\mathrm{p}<0.0001)$.

\section{Discussion and conclusions}

Patients with worse self-Image have an "adequate" perception of the deformity, at least so "adequate" than those with a better self-image, but they have just bigger curves. Moreover the Self Perception of Trunk Deformity measured by TAPS could be considered a variable intermediate between Cobb Angles and Self Image, as TAPS is a recognition of the deformity while SRS-Self Image is a self-evaluation about the body experience, likely influenced by other emotional and cognitive factors.

\section{Authors' details \\ ${ }^{1}$ Elena Salva Institut, Barcelona, Spain. ${ }^{2}$ Institut Reçerca Vall Hebron, Barcelona, Spain.}

Published: 4 December 2014

doi:10.1186/1748-7161-9-S1-075

Cite this article as: Rigo et al:: Health related quality of life in untreated and treated patients with AIS. Study III: trunk appearance and selfimage. Scoliosis 2014 9(Suppl 1):O75.

${ }^{1}$ Elena Salva Institut, Barcelona, Spain

Full list of author information is available at the end of the article 